\title{
FORMAÇÃO DE PROFESSORES DE PLE: aprendizagem orientada pela avaliação no e pelo teletandem
}

\author{
PFL TEACHER EDUCATION: learning oriented assessment in the teletandem context
}

\author{
FORMACIÓN DE PROFESORES DE PLE: aprendizaje orientado por la evaluación en el y por el \\ teletandem
}

Gabriela Rossatto Franco ${ }^{1}$

Viviane Aparecida Bagio Furtoso ${ }^{2}$

1. Graduada em Letras (Português e Inglês). Doutoranda em Estudos da Linguagem pela Universidade Estadual de Londrina (UEL). E-mail: gabriela.rf@hotmail.com.

2. Graduada em Letras Anglo-Portuguesas. Doutora em Estudos Linguísticos. Pós-doutora na Georgetown University - Estados Unidos. Docente efetiva do Departamento de Letras Estrangeiras Modernas da Universidade Estadual de Londrina (UEL), E-mail: viviane@ uel.br.

RESUMO: Apesar do potencial das práticas de teletandem para a aprendizagem de línguas e para a formação de professores, alguns estudos apontam lacunas referentes à formação, especificamente, de professores para o ensino de Português como Língua Estrangeira (PLE). Portanto, visando a colaborar com essa área, relatamos a experiência de um curso de extensão de formação de professores no qual os participantes realizaram interações de teletandem e leituras para a discussão de especificidades do ensino de PLE, além de participarem presencialmente de encontros para a mediação. A partir de affordances para o desenvolvimento de professores no teletandem, o curso foi conduzido com base na avaliação como diagnóstica, formativa e, portanto, orientadora da aprendizagem, permitindo-nos (re)orientar nossa prática pedagógica a partir das respostas fornecidas pelos parceiros brasileiros a uma Ficha de Acompanhamento / Autoavaliação de Teletandem (FAT). Como considerações preliminares, o estudo identificou affordances do teletandem para a formação de professores de PLE, a saber: criar empatia para a prática de idiomas por meio da telecolaboração, refletir sobre a língua materna como língua do outro $\mathrm{e}$ as implicações que isso oferece para a atuação do professor de línguas, fornecer feedback cultural considerando a diversidade e a pluralidade, praticar tipos diferentes de feedback linguístico frente à cultura de aprender do parceiro e ampliar o uso de recursos tecnológicos para o ensino de línguas.

Palavras-chave: PLE; Formação de Professores; Avaliação; Telecolaboração.
ABSTRACT: Despite teletandem practices having been shown as potential contexts for both language learning and teaching, studies have identified some gaps for teacher education of Portuguese as a Foreign Language (PFL). Thus, aiming to collaborate to PFL teacher education, this paper presents the experience of a course in which the participants took part in teletandem sessions in order to learn and practice a foreign language and experience teaching PFL, read the suggested papers to discuss the features of PFL teaching, and also participated in the face to face meetings (mediations) organized by the teacher educators. Considering the affordances for teacher development in teletandem, the course was carried out through the concept of learning oriented assessment. Therefore, assessment operated as a learning advisor which helped the teacher educators led the pedagogical practice through the answers from Brazilian students to a Self-Assessment/Tracking Teletandem Sheet. As preliminary results, it is possible to indicate some affordances of teletandem for PFL teachers: to create empathy to language practice through telecollaboration, to reflect on the mother tongue as a foreign language and on its implications to the teacher when one teaches PFL, to provide cultural feedback considering diversity and plurality, to practice different types of linguistic feedback regarding the students' culture of learning, and lastly to increase the use of technological resources to language teaching.

Keywords: PFL; Teacher education; Assessment; Telecollaboration.
RESUMEN: A pesar del potencial de las prácticas de teletandem para el aprendizaje de lenguas y para la formación de profesores, algunos estudios apuntan huecos referentes a la formación de profesores para la enseñanza de Portugués como Lengua Extranjera (PLE). Por eso, buscando llenar esas lagunas, reportamos la experiencia de un curso de extensión de formación de profesores en el cual los participantes realizaron interacciones de teletandem y lecturas para la discusión de especificidades de la enseñanza de PLE, además, participaron presencialmente de encuentros para la mediación colectiva por las formadoras. Desde affordances para el desarrollo de profesores en el teletandem, el curso fue conducido con base en la evaluación como diagnóstica, formativa y, por lo tanto, orientadora del aprendizaje, lo que nos permitió (re)orientar nuestra práctica pedagógica a partir de las respuestas obtenidas de los parceros brasileños en una Ficha de Acompañamiento / Autoevaluación de Teletandem (FAT). Como consideraciones preliminares, el estudio identificó affordances del teletandem para la formación de profesores de PLE, a saber: crear empatía para la práctica de idiomas por medio de la telecolaboración, reflexionar sobre la lengua materna como lengua del otro y en sus implicaciones para la actuación del profesor de lenguas, ofrecer feedback cultural que considera la diversidad y la pluralidad, practicar modos diferentes de feedback lingüístico con relación a la cultura de aprender del parcero y ampliar el uso de recursos tecnológicos para la enseñanza de lenguas.

Palabras-clave: PLE; Formación de Profesores; Evaluación; Telecolaboración 


\section{Introdução}

A globalização tem causado mudanças significativas no modo de viver, consumir e se relacionar. Entre tantos efeitos advindos desse fenômeno, a comunicação é diretamente ressignificada e, consequentemente, são necessárias mudanças nas formas de se ensinar e aprender línguas, já nos alertavam Block e Cameron (2002). Com isso, temos buscado conduzir nossos estudos de modo a entender melhor o que deve ser considerado pelo formador de professores diante dessas mudanças e ressignificações.

As especificidades concernentes ao ensino de Português como Língua Estrangeira (PLE) ganham holofotes na agenda de pesquisa no Brasil (ALMEIDA FILHO, 2011; FURTOSO, 2011; MENDES, 2011; ROCHA; GILENO, 2015). Em um levantamento acerca de pesquisas nessa área em nível de Mestrado e Doutorado nos programas de pós-graduação das universidades brasileiras (FURTOSO, 2015), destacam-se temáticas que contemplam a avaliação como objeto de estudo em contextos de ensino e aprendizagem. Em se tratando de ambientes telecolaborativos, autoras como Kfouri-Kaneoya (2008), Furtoso (2011) e Franco (2016) apontam reflexões acerca do ensino de PLE, direcionando-nos a reflexões a respeito da formação do professor nesse contexto.

Desse modo, dado o potencial da telecolaboração para o ensino-aprendizagem de línguas e as lacunas referentes à formação de professores de PLE, o presente estudo explora as contribuições de um curso de extensão que teve o teletandem, um espaço telecolaborativo de ensino-aprendizagem de línguas, como metodologia e como objeto de estudo ao mesmo tempo. Como parte do curso, os participantes realizaram interações de teletandem com o intuito de praticarem uma língua estrangeira e, concomitantemente, vivenciarem a experiência de ensinar PLE a um parceiro estrangeiro. A formação desses professores foi também propiciada por discussões teórico-práticas acerca de aspectos linguísticoculturais e avaliativos durante encontros presenciais mediados pelas formadoras.

A escolha do teletandem como espaço de prática de uma língua estrangeira, bem como de prática de ensino de PLE no curso por nós proposto, deve-se às affordances ${ }^{1}$ do teletandem para o desenvolvimento profissional de professores, que os oportunizam mudar percepções sobre o ensino e aprendizado de línguas, forjar novas identidades, vivenciar a língua e apropriar-se de / implementar práticas semelhantes no ensino de línguas (EL KADRI, 2018).

Considerando, portanto, tais affordances e buscando contemplá-las na prática dos participantes brasileiros, o curso foi conduzido buscando respaldo em uma concepção de avaliação como orientadora do processo de ensino e aprendizagem (BONESI; SOUZA, 2006; CARLESS, 2007; FURTOSO, 2011; SCARAMUCCI, 2006) dentre outros, o que permitiu acompanhar o desempenho dos participantes como professores de PLE, ao passo que também (re)orientava a prática pedagógica das formadoras na condução para os encontros presenciais, tendo sempre o diagnóstico como ponto de partida para as intervenções.

Para detalhar melhor essa experiência, exploraremos, inicialmente, neste artigo, a telecolaboração e o teletandem a fim de caracterizarmos tais espaços de aprendizagem online para, então, abordarmos a questão do ensino e da formação de professores de PLE no curso de extensão intitulado Abordando o ensino de Português para Falantes de Outras Línguas por meio da prática de telecolaboração: espaço para

\footnotetext{
${ }^{1}$ O termo affordance foi proposto por Gibson (1979, apud van LIER, 2000) para designar a relação mútua entre um organismo e o ambiente no qual se insere. As affordances seriam tudo o que o ambiente fornece a esse organismo, seja para o bem ou para o mal, dependendo da necessidade e da capacidade de percepção do agente. Posteriormente, Van Lier (2000) apresenta esse conceito no âmbito de aprendizagem de línguas. Para o autor, "o meio ambiente é cheio de linguagem e fornece oportunidades de aprendizagem para o aprendiz participante e ativo." (van LIER, 2000, p. 252, nossa tradução). No contexto de aprendizagem de línguas, os propiciamentos, tradução de Paiva para affordances, "não são os mesmos para todos os aprendizes, pois há contextos que favorecem mais oportunidades para a aprendizagem de uma segunda língua do que outros" (PAIVA, 2009, p. 3). Para uma leitura mais detalhada sobre o conceito de affordance, sugerimos o estudo de Paiva (2009).
} 
formação de professores de línguas. Para finalizar, apresentaremos uma breve síntese apreciativa do que foi o curso para os professores e para as formadoras, na perspectiva de deixar pistas para a retomada do ciclo a partir da avaliação da experiência.

\section{Telecolaboração e Teletandem}

O avanço da tecnologia tem corroborado a disposição de diversos ambientes virtuais para a promoção do ensino-aprendizagem de línguas. A telecolaboração, por exemplo, permite que estudantes distantes geograficamente vivenciem a experiência de aprendizagem colaborativa virtual (O'DOWD, 2016).

Para O'Dowd (2016), diferentemente de outros espaços de aprendizagem online, a telecolaboração se caracteriza pelo enfoque no diálogo intercultural e por abordagens colaborativas em que conhecimento e entendimento são construídos através da interação e da negociação.

No entanto, por ser um espaço bastante vulnerável a conflitos, sejam de ordem pessoal, como de ordem logístico-tecnológica, o papel do professor, ou o que vamos chamar de mediador neste estudo, é fundamental para "iniciar, desenvolver e monitorar as trocas telecolaborativas para a aprendizagem de línguas.”' (MÜELLER-HARTMMAN, 2012, p. 172, apud O’DOWD, 2015, p. 65). Logo, é função do mediador preparar os participantes para as interações online, acompanhar o processo e fazer as intervenções necessárias.

Entre as modalidades de telecolaboração, destacamos o teletandem, que se caracteriza pelo uso de recursos de videoconferência que possibilitam a comunicação entre estudantes do mundo todo interessados em aprender um novo idioma por meio de situações de uso real da língua (VASSALLO; TELLES, 2009). O teletandem fundamenta-se em três princípios característicos e adaptados do tandem: prática de línguas em separado, reciprocidade e autonomia (BRAMMERTS, 1996, apud VASSALLO; TELLES, 2009).

No caso do curso por nós proposto, as interações de teletandem ocorreram conforme o modelo de teletandem interinstitucional, que "prevê um acordo entre instituições de ensino superior com interesse em aprender e ensinar línguas estrangeiras” (RAMOS; CARVALHO; MESSIAS, 2013, p. 4). Desse modo, estabeleceu-se uma parceria entre uma universidade estadual brasileira e uma universidade estadunidense.

As interações de teletandem devem ser organizadas de modo que os dois parceiros tenham tempo igual para praticar a língua que estão aprendendo sem misturá-las durante o tempo de cada uma. Logo, o participante, além de aprendiz de língua estrangeira, é deslocado para a posição de professor de sua língua materna ou de proficiência, devendo, portanto, fornecer feedback a seu parceiro. Sendo assim, o teletandem propicia, além da oportunidade de contato intercultural, um ambiente favorável à aprendizagem de uma língua estrangeira e ao ensino da própria língua materna ou de proficiência.

No entanto, uma vez que as interações ocorrem por meio de ferramentas de videoconferência e, em alguns casos, os participantes as realizam de suas próprias casas, há o risco de que tais encontros transformem-se em uma conversa informal ou um simples bate-papo, ficando o foco principal (aprendizagem de línguas) em segundo plano.

Para evitar que o teletandem se distancie de seus objetivos principais referentes à aprendizagem de línguas, a mediação desempenha um papel importante, uma vez que, segundo Little (2003) (apud SALOMÃO; SILVA; DANIEL., 2009), além do suporte técnico e operacional para a realização das

\footnotetext{
${ }^{2}$ No original “... the role of the teacher is crucial in initiating, developing and monitoring telecollaborative exchanges for language learning" (MÜELLERHARTMMAN, 2012, p. 172, apud O'DOWD, 2015, p. 65).
} 
interações, o mediador também pode auxiliar o participante com relação à comunicação intercultural e "aos aspectos complexos da língua em si e de ensino e aprendizagem de línguas" (SALOMÃO; SILVA; DANIEL, 2009, p. 81).

A mediação ocorre ao final de cada interação e é conduzida por um mediador de teletandem que pode ser um professor da instituição, um aluno da pós-graduação/graduação, e/ou um pesquisador de teletandem.

Na subseção a seguir, exploraremos o potencial da telecolaboração para o ensino e para a formação de professores de PLE.

\section{PLE em Telecolaboração}

Ao analisar os aspectos linguísticos emergentes nas interações de teletandem, Franco (2016) investigou o modo como os participantes brasileiros (futuros professores de línguas) corrigiam e forneciam explicações sobre sua língua materna a seus parceiros. A autora constatou dificuldades e equívocos cometidos pelos alunos ao esclarecer dúvidas sobre a língua portuguesa. O mesmo foi observado nos resultados de Furtoso (2011).

Com base em tais estudos (FRANCO, 2016; FURTOSO, 2011), dialogamos com Kfouri-Kaneoya (2008; 2009), acreditando que experiências escolares anteriores corroboram o modo como os alunos participantes de teletandem concebem a língua, implicando, consequentemente, a maneira como oferecem correções e explicações sobre a mesma a seus parceiros. Portanto, é comum que esses alunos adotem (não apenas no teletandem, mas na sala de aula presencial, e até mesmo no âmbito pessoal/social) explicações baseadas em questões estruturais sem enfatizar os efeitos e usos sociais da língua (FRANCO, 2016).

Outros estudos nesse contexto ratificam nossa reflexão sobre o ensino de PLE. Furtoso e Ferreira (2016), por exemplo, apontam a perspectiva do aprendiz de português a partir da experiência com a prática de teletandem. Com base nas respostas de um grupo de aprendizes de português de uma universidade estadunidense, os autores captaram, nas palavras dos próprios aprendizes, queixas como correção insuficiente, ausência de exercícios de sistematização da língua após as sessões de teletandem e ausência de feedback do parceiro brasileiro.

Sendo assim, apesar do grande potencial do feedback entre os pares de teletandem durante as interações (FURTOSO, 2011), observamos que, muitas vezes, os participantes não exploram esse recurso de forma a causar impacto positivo na aprendizagem do parceiro estrangeiro de teletandem, aprendiz de português.

Considerando, também, que muitos brasileiros realizam o teletandem com o intuito de aprimorar o desempenho em uma língua estrangeira, faz-se ainda mais compreensível depararmo-nos com lacunas a respeito do ensino de PLE nesse contexto.

Ao explorar aspectos da formação de professores de PLE, Furtoso (2001) reconhece que ensinar português para falantes de outras línguas apresenta suas próprias especificidades e que ser um usuário competente de português não garante que se esteja preparado para ensiná-la. Os dados coletados em 2001, respaldados tanto por estudos anteriores quanto posteriores, nos levam a corroborar a autora no que diz respeito à necessidade de formação específica para atuar na área de PLE.

Em estudo posterior, Furtoso (2011) apresenta uma compilação das pesquisas na área de português para falantes de outras línguas e as especificidades demandadas para esse contexto. Além da importância 
de um feedback efetivo ${ }^{3}$ no que diz respeito aos aspectos de estrutura da língua portuguesa, como já destacado nas palavras dos participantes da pesquisa de Furtoso e Ferreira (2016), chamamos a atenção para o papel fundamental que o parceiro brasileiro tem no preenchimento de lacunas acerca de aspectos interculturais durante as interações de teletandem.

No que concerne ao último ponto supracitado, para O'Dowd (2015), o professor, no contexto de telecolaboração, deve ser capaz de identificar as causas de problemas interculturais e adotar técnicas e estratégias para lidar com tais problemas. Essa capacidade integra as competências organizacionais, juntamente com as seguintes particularidades referentes ao professor telecolaborador: competências pedagógicas, competências digitais, e atitudes e crenças (O’DOWD, 2015).

Considerando o potencial do teletandem para a formação de professores de PLE, destacamos algumas barreiras que precisam ser exploradas, a saber: direcionar o foco do parceiro brasileiro para o fato de ele estar, também, no papel de professor de português e não apenas de aprendiz de uma língua estrangeira, o que demanda reflexão sobre a língua e sobre o ensino de línguas; proporcionar letramento em avaliação para o fornecimento de feedback linguístico-cultural mais efetivo; trazer para o bojo da mediação a explicitação do conceito de uso da língua mediado pela negociação de significados durante a interação de teletandem, dentre outras especificidades inerentes ao contexto de ensino de PLE.

Portanto, cientes das lacunas mencionadas, reiteramos a importância da mediação para explorar as especificidades necessárias para o ensino de PLE, bem como para auxiliar o participante de teletandem a aproveitar as affordances que esse contexto oferece para sua formação como professor dessa língua.

Passemos, então, a relatar e levantar questões sobre o ensino e a formação de professores de PLE no curso de extensão intitulado Abordando o ensino de Português para Falantes de Outras Línguas por meio da prática de telecolaboração: espaço para formação de professores de línguas, ofertado no segundo semestre de 2019, como curso de extensão da Universidade Estadual de Londrina, no Brasil, em parceria com Universidade de Arkansas, nos Estados Unidos, para a prática de teletandem.

\section{Abordando o ensino de PLE por meio da prática de telecolaboração: espaço para formação de professores de línguas}

Com o objetivo de avançar na compreensão de como podemos explorar as barreiras que os parceiros brasileiros enfrentam quando são expostos às interações de teletandem sem formação específica na área de PLE, buscamos respaldo nos resultados do estudo de El Kadri (2018), que caracterizou as affordances acerca do desenvolvimento de professores em três grandes categorias: a) desenvolvimento linguístico, b) tecnologia e c) desenvolvimento profissional de professores. Para o presente estudo, vamos nos deter nas affordances referentes ao último aspecto, já que o nosso foco foi propor um curso de formação de professores de PLE que explorasse o teletandem como um espaço de desenvolvimento profissional para além de seu objetivo primeiro, que sempre foi a prática de uma língua estrangeira.

Com isso, almejávamos colocar os professores em contato com suas percepções sobre o ensino e a aprendizagem de línguas, desafiá-los a reconhecer sua identidade como professor de sua própria língua materna, o português, além de levá-los a ampliar seus conhecimentos sobre a telecolaboração e suas affordances para a aprendizagem de línguas estrangeiras, podendo, inclusive, refletir sobre a adoção de práticas de teletandem com seus grupos de aprendizes de línguas estrangeiras.

\footnotetext{
${ }^{3}$ Segundo Schwartz e White (apud PAIVA, 2003), os alunos consideram como feedback efetivo aquele que é: 1. imediato, oportuno e completo; 2. formativo e dirigido ao grupo; 3. avaliativo; 4. construtivo, substantivo e que dê suporte; 5 . específico, objetivo e individual; 6. consistente. (FURTOSO, 2011, p. 140).
} 
Uma postura crítico-reflexiva, no entendimento de Calderhead e Gates (1993, apud GIMENEZ, 1998), pode ser alcançada quando os cursos de formação apresentam um ou mais objetivos a fim de que os professores possam:

... i. analisar, discutir e avaliar suas próprias práticas, adotando uma postura analítica com relação ao ensino; ii. apreciar o contexto sócio-político no qual estão inseridos, auxiliando-os a reconhecer que o ensino é social e politicamente condicionado e que a tarefa dos professores é a de analisar esse contexto; iii. levantar questões éticas e morais implícitas nas práticas de sala de aula, fazendo inclusive uma análise crítica de suas próprias concepções sobre um ensino eficiente; iv. desenvolver suas próprias teorias sobre a prática educacional, compreendendo e desenvolvendo princípios bem fundamentados para seu trabalho em sala de aula; v. influenciar decisões futuras sobre educação e participar mais ativamente das decisões educacionais (GIMENEZ, 1998, p. 260-261).

Para isso, organizamos um curso de extensão que partia de um planejamento prévio bastante flexível em termos de conteúdo, de modo a considerar as dúvidas e as necessidades do público-alvo. Para que essas dúvidas e necessidades fossem identificadas durante o curso, apoiamo-nos em uma concepção de avaliação diagnóstica e formativa, e, portanto, orientadora da aprendizagem, de modo a promover reflexão para os professores envolvidos e subsídios para o formador fazer as intervenções durante o processo. $\mathrm{O}$ curso, o instrumento de avaliação adotado e a condução do nosso trabalho serão abordados a seguir.

\section{O curso de extensão e os participantes brasileiros}

Considerando, então, as affordances do teletandem para o desenvolvimento de professores de PLE e a avaliação como orientadora da aprendizagem, foi ofertado um curso de extensão visando a estabelecer um contexto de reflexão e ação sobre o ensino de PLE. O curso aqui apresentado também foi uma experiência piloto para a coleta de dados para uma tese de doutorado em andamento naquele momento.

A iniciativa foi ofertada no segundo semestre de 2019, na Universidade Estadual de Londrina (UEL). Contou com 10 participantes brasileiros, sendo 05 estudantes do curso de graduação em Letras Inglês da UEL e 05 estudantes da pós-graduação em Estudos da Linguagem. Dos 10 participantes, 02 fizeram interações português-inglês e português-espanhol (tiveram, portanto, dois parceiros estrangeiros cada $\left.^{4}\right), 01$ parceria em português-espanhol e as outras 05 parcerias em português-inglês.

Com carga horária total de 20 horas, o curso contemplou as seguintes atividades: quatro interações de teletandem (divididas entre o período de 18 de outubro a 24 de novembro de 2019), cinco encontros presenciais $^{5}$ (mediações realizadas entre 17 de outubro a 12 de dezembro de 2019), preenchimento de quatro fichas de acompanhamento em teletandem (FAT) (uma para cada interação) e leituras de textos teóricos.

\section{A ficha de acompanhamento/autoavaliação de teletandem}

Por que autoavaliação? A autoavaliação consiste na apreciação de si próprio a respeito de suas limitações, conquistas e resultados ainda a serem alcançados. De acordo com Haydt (1995),

\footnotetext{
${ }^{4}$ Dois parceiros brasileiros se voluntariaram a realizar duas parcerias cada, já que o número de alunos do curso de português da universidade estadunidense era maior do que o número de inscritos no curso de extensão da UEL. Como o foco do nosso estudo recai sobre a formação dos parceiros brasileiros para atuarem como professores de PLE, os parceiros estrangeiros não são considerados como participantes para este artigo.

${ }^{5}$ Os encontros presenciais do curso de extensão configuram-se como as mediações de teletandem, portanto, ambos os termos serão utilizados intercambiavelmente nesta seção.
} 
a prática da autoavaliação cria condições para que o aluno tenha uma participação mais ampla e ativa no processo de aprendizagem, porque ele tem oportunidade de analisar seu progresso nos estudos (o que aprendeu e o que poderia ter aprendido) bem como as atitudes e o comportamento diante do professor e dos colegas. Além disso, a autoavaliação tem uma função pedagógica, pois a consciência dos próprios avanços, limites e necessidades é a melhor forma de conduzir ao aperfeiçoamento (HAYDT, 1995, p. 300).

Sobre o papel do professor nesse processo, Kiely (2018) destaca sua participação ao auxiliar o aluno na autorreflexão, identificar os próximos passos a serem tomados e encorajá-los a assumirem o comando de sua aprendizagem.

Essas características da autoavaliação se alinham muito bem com os contextos de aprendizagem telecolaborativos, uma vez que professor e parceiros mais proficientes na língua-alvo "passam a ser mediadores da aprendizagem, enquanto o estudante torna-se mais ativo e autonômo durante as interações online ao avaliar seu próprio desempenho" (SILVEIRA, 2017, p. 16). Outros estudos ratificam resultados que apontam a importância da autoavaliação para o processo de aprendizagem de línguas no teletandem (CAVALARI, 2009; CAVALARI; FRESCHI, 2018; FURTOSO, 2011; FURTOSO; FERREIRA, 2016).

Já em 2011, Furtoso ressaltava "a possibilidade de se pensar em uma ficha de autoavaliação e avaliação por pares para o acompanhamento da aprendizagem do futuro professor de línguas” (p. 221). A autora defendia que "o feedback sobre o processo de aprender a ensinar também pode oferecer subsídios para a otimização da aprendizagem no contexto de formação de professores de línguas" (FURTOSO, 2011, p. 221).

Desse modo, a FAT (Apêndice 1) foi adotada no curso de extensão para formação de professores de PLE da UEL como um instrumento que serviria tanto para desenvolver a autorregulação e autonomia (SILVEIRA, 2017) dos futuros professores de PLE, como para subsidiar a condução das mediações pelas formadoras. Segundo Miquelante et al. (2017), a autoavaliação alinha-se à avaliação diagnóstica uma vez que permite "ao estudante se 'enxergar' nesse processo e por ajudar o professor a direcionar as atividades futuras e a delimitar o conteúdo dos módulos" (MIQUELANTE et al., 2017, p. 283). No nosso caso, não tivemos módulos nos moldes do estudo de Miquelante, mas tomávamos decisões sobre o conteúdo a ser abordado e discutido durante os encontros presenciais com base nas respostas registradas nas FAT pelos participantes brasileiros após cada interação de teletandem. Logo, o curso foi organizado de modo que, após cada interação, a FAT fosse preenchida pelos participantes brasileiros e analisada imediatamente pelas formadoras para que as intervenções fossem feitas antes da realização da interação seguinte.

\section{Dados gerados ao longo do curso}

Sob a perspectiva crítico-reflexiva para o desenvolvimento de professores que embasou nossa proposta, a pesquisa torna-se um elemento chave, tanto para o formador quanto para o próprio futuro professor e, por isso, faz-se relevante destacar aqui como e que tipo de informações foram coletadas durante o período de realização do curso de extensão (lembrando que o mesmo teve duração de 20 horas).

Os dados ${ }^{6}$ gerados foram resultado de $41 \mathrm{FAT}$, preenchidas após cada interação de teletandem pelos parceiros brasileiros, e 45 gravações em áudio e vídeo de interações de teletandem ${ }^{7}$ (aproximadamente 37

\footnotetext{
${ }^{6} \mathrm{O}$ estudo foi aprovado pelo Comitê de Ética, permitindo, assim, a coleta dos dados usados para este artigo. Número do parecer: 3.814 .023$.

${ }^{7}$ Considerando o número de parcerias (12) e de interações (4), teríamos um total de 48 FAT e 48 gravações de interações. No entanto, alguns participantes não conseguiram cumprir as 4 interações (totalizando 45) e alguns não entregaram as 4 FAT (totalizando apenas 41).
} 
horas de gravação ${ }^{8}$, sendo metade do tempo dedicado à interação em português e metade à língua estrangeira da parceria).

Por uma limitação de tempo durante o curso, as formadoras não conseguiram cruzar dados das FAT e das gravações em áudio e vídeo, o que ficou para a tese de doutorado. Mas adiantamos que a expectativa é de que o cruzamento de informações das fontes geradoras, além do diálogo com os participantes durante os encontros presenciais, é promissor para nos dar luz à busca por caminhos para avançarmos no desenvolvimento de professores de PLE.

Apenas como uma amostra de como o curso foi conduzido com o suporte das FAT, apresentaremos algumas linhas na subseção a seguir.

\section{Um enquadramento da condução do curso e considerações preliminares}

O curso foi conduzido sob um viés diagnóstico e formativo, objetivando orientar a aprendizagem dos participantes acerca do ensino de PLE.

Os cinco encontros presenciais foram delineados a partir das análises das FAT pelas formadoras. As respostas foram sendo agrupadas por incidências, ou seja, as formadoras verificavam que tipo de dúvida e de necessidade os participantes brasileiros apresentavam com maior recorrência para cada um dos aspectos contemplados nas FAT, de modo que a mediação fosse preparada e o curso (re)organizado durante o processo de aprender a ensinar PLE.

$\mathrm{O}$ aspecto mais recorrente em cada interação era selecionado pelas formadoras, que enviavam texto(s) para leitura prévia dos participantes antes dos encontros presenciais. Desse modo, o encontro presencial ocorria da seguinte forma: a mediadora retomava alguns dos principais aspectos mencionados por eles nas FAT (divididos em: linguísticos, culturais e metodológicos); explorava o tema principal com base na(s) leitura(s) proposta(s); e, por fim, estabelecia um momento com os participantes para discussão do tema, relacionando-os com suas práticas no teletandem.

A primeira mediação contemplou informações gerais sobre o curso e algumas orientações para a primeira interação de teletandem, tais como: trocar conhecimentos interpessoais, negociar correções com os parceiros, pensar sobre temas a serem abordados ao longo das interações, entre outras.

Nas FAT da primeira interação, os participantes relataram que evitaram corrigir e interferir na fala do parceiro estrangeiro, o que se mostra compreensível e aceitável até pelo fato de ser o primeiro contato da parceria e, portanto, faz-se importante estabelecer um canal de diálogo e de negociação de condutas. No entanto, uma vez que os participantes brasileiros estavam participando do curso e, neste caso, as interações de teletandem compunham as atividades para formação de professores de PLE, nossa segunda mediação explorou o tema feedback ${ }^{9}$.

Para que a avaliação desempenhe o papel de orientar e colaborar com a aprendizagem, é importante que o professor forneça feedback a respeito das produções do aluno. O feedback pode ser empregado a fim de destacar o bom desempenho do aluno ou aperfeiçoá-lo (HAYDT, 1995).

Para Hattie (2012), para que seja eficaz, o feedback precisa ser mais descritivo a fim de fornecer informações e orientações, destacar qualidades e apontar estratégias. Tal processo de verificação auxilia os

\footnotetext{
${ }^{8} \mathrm{O}$ número total de horas de gravação (37 horas) deve-se ao fato de que cada interação durava, em média, 50 minutos. Além disso, houve casos de problema de conexão ou questões pessoais (compromissos, imprevistos, atrasos), portanto, algumas interações apresentaram menor tempo de duração.

${ }^{9}$ A leitura sugerida para esse encontro foi “A avaliação por pares no teletandem institucional integrado: um estudo de caso sobre o feedback linguístico nas sessões orais em português" (FRESCHI, 2017).
} 
alunos a se tornarem mais conscientes de como conduzir seu próprio entendimento (FICHER; FREY, 2007).

Ao investigarem a proficiência oral no contexto teletandem, Consolo e Furtoso (2015) relacionam o papel dofeedback entre os parceiros à avaliação formativa. Para os autores, o feedback durante a interação colabora para a produção linguística e para o fluxo da conversa, "tornando o processo [de oferecer feedback] um exemplo de aprendizagem de língua contextualizado e significativo ${ }^{10}$." (CONSOLO; FURTOSO, 2015, p. 677).

As FAT das interações seguintes a esse segundo encontro já apresentaram mais relatos de momentos de correção e explicação e, inclusive, preocupação e dificuldades por parte dos participantes brasileiros ao fazê-lo. A maioria dos participantes também demonstrou maior atenção a aspectos linguísticos da língua portuguesa. Tais fatos demonstram um efeito possivelmente decorrente da mediação prévia sobre feedback.

O terceiro encontro do curso (após a segunda interação dos participantes) foi voltado para a questão dos estereótipos, já que a maioria das respostas às FAT tocavam em alguns pontos de fragilidade ao abordar questões culturais. Estudos mostram que a abordagem de temas como celebrações, músicas, comidas típicas, entre outros aspectos que compõem os costumes e culturas de um país/região, são assuntos recorrentes em interações de teletandem (FRANCO; RAMPAZZO, 2016; TELLES; ZAKIR; FUNO, 2015; ZAKIR, 2015).

Conforme já implicado nos resultados do estudo de Furtoso (2011), a co-construção da conversa(ção), no teletandem, vai sendo permeada também por preenchimento de lacunas de conhecimentos culturais por um parceiro e por outro. Neste sentido, a autora destaca a importância da qualidade do feedback no preenchimento dessas lacunas de aspectos interculturais nas interações de teletandem. Houve um envolvimento significativo dos participantes durante esta mediação de modo que suas percepções sobre língua e sobre ensino e aprendizagem foram externalizadas, trazendo também à baila questões que os remeteram às suas identidades como falantes de português e professores de PLE.

Ao explorarmos esse tema no curso bem como promover, aos alunos, a oportunidade de ensino de PLE em um contexto telecolaborativo, corroboramos a proposta de Mendes (2011) sobre uma abordagem de ensino intercultural em que se deve adotar uma visão dinâmica e versátil da cultura. Por meio dessa visão, segundo a autora, são abordadas tanto informações culturais (estatísticas, eruditas e do cotidiano) quanto símbolos e práticas a serem interpretados a partir de uma perspectiva intercultural. Nessa abordagem intercultural, conforme explicitado por Mendes (2011) e verificado no teletandem, a língua medeia os mundos em contato, permitindo que os envolvidos conheçam a língua e através dela.

Os participantes se engajaram de tal forma que decidimos dar continuidade ao tema da interculturalidade no quarto encontro presencial. Para tanto, analisamos o material didático "Pode entrar: Português do Brasil para refugiadas e refugiados" (OLIVEIRA et al., 2015) no que concerne à abordagem dos aspectos culturais no ensino de PLE. Também exploramos o Portal do Professor de Português Língua Estrangeira/Língua Não Materna $^{11}$ para que os participantes conhecessem essa plataforma, que disponibiliza materiais em diferentes variantes da língua portuguesa para o ensino de PLE. Várias questões que foram trazidas nas FAT foram exploradas também no material analisado, de modo a levar os participantes do curso a ampliarem seus conhecimentos teórico-práticos sobre os desafios que ser um "representante" da língua-alvo implica.

\footnotetext{
${ }^{10}$ No original "making the process an example of contextualized and meaningful language learning." (CONSOLO; FURTOSO, 2015, p. 677).

${ }^{11}$ https://ppple.org/
} 
A quinta e última mediação (após a quarta e última interação de teletandem) explorou aspectos linguístico-discursivos do ensino de $\mathrm{PLE}^{12}$. A escolha do tema justifica-se pelas dificuldades relatadas pelos participantes no que concerne ao ensino de tais aspectos durante as interações de teletandem. Além disso, a leitura proposta explorava um livro didático de ensino de PLE, o que possibilitou aos participantes conhecerem mais um material para esse fim, bem como analisá-lo com base nos conhecimentos e experiências adquiridos ao longo do curso.

O artigo sugerido explorou aspectos do livro relacionados a visões de linguagem e de aprendizagem, autonomia do aprendiz, capacidades de linguagem (de ação, discursivas e linguístico-discursivas), habilidades trabalhadas e questões culturais. Desse modo, os participantes puderam discorrer sobre a importância desses pontos em um material didático para ensino de PLE para além de uma análise observatória, mas com uma perspectiva crítica, uma vez que, naquele momento, já haviam tido contato com outras leituras referentes ao ensino de PLE, bem como a experiência de ensinar a língua.

Embora não tenhamos cruzado os dados das FAT e das gravações, o acompanhamento pelas respostas registradas nas FAT e o diálogo ${ }^{13}$ com os alunos durante os encontros presenciais nos permitem afirmar que momentos de correção, explicação e feedback por parte dos parceiros brasileiros foram sendo mais frequentes ao longo do curso e com maior qualidade. Também observamos a preocupação deles ao explorarem aspectos culturais sem reforçar estereótipos e o uso de recursos tecnológicos variados (chat, vídeos, imagens, compartilhamento de tela, músicas, entre outros). Outros dois aspectos interessantes verificados dizem respeito à melhora na fluidez da conversa (em decorrência do aperfeiçoamento do desempenho do parceiro estrangeiro na língua portuguesa) e às reflexões e conscientização por parte dos parceiros brasileiros sobre aspectos da língua portuguesa suscitadas a partir das interações de teletandem, aspectos esses que, até então, passavam despercebidos para os (futuros)professores de línguas.

Os trechos que seguem ilustram os pontos supracitados com registros de Raquel ${ }^{14}$ e Natália sobre fornecimento de correções, feedback e explicações, e de Yasmin sobre o fluxo da conversa.

"Tive dificuldade em explicar a palavra 'compensa' e 'destoar'. Utilizei bastante exemplos e sinônimos... e até linguagem corporal para me fazer entendida." (Raquel, FAT 3).

"Como não tínhamos estabelecido no início a forma de feedback, fiquei em dúvida como abordar os erros, ela falou 'pero' no lugar de 'mas' e fiquei sem jeito de corrigir." (Natália, FAT 2).

"Conversamos bastante em Inglês, e vejo que ela ainda se apoia na sua língua materna” (Yasmin, FAT 3).

Ratificamos, portanto, as dificuldades em corrigir e explicar aspectos da língua portuguesa por parte dos parceiros brasileiros, bem como o uso da língua de proficiência (inglês ou espanhol no caso dos participantes estrangeiros deste estudo) para a comunicação por parte dos estadunidenses.

No que tange ao fluxo da conversa, Leandro, por exemplo, relata até mesmo desconforto na primeira interação com a sua parceira em decorrência de seu nível de proficiência em português, o que atrapalhou o

${ }^{12}$ Leitura sugerida: "O desafio de se ensinar português para falantes de outras línguas: análise linguístico-discursiva de um livro didático para o ensino de PLE" (ROSA, 2012).

${ }^{13}$ Uma outra limitação que apontamos a partir deste curso piloto foi o fato de não termos gravado os encontros presenciais. Hoje, vislumbrando a possibilidade de replicar este curso na modalidade a distância também para os encontros de mediação, teríamos mais recursos para gravar as mediações e, assim, ter mais uma fonte de geração de dados para formador e professor em formação.

${ }^{14}$ Os nomes dos participantes foram substituídos por nomes fictícios a fim de preservar suas identidades. 
fluxo da conversa. Porém, nas FAT seguintes ele apresenta comentários positivos a respeito do desempenho da parceira o que, consequentemente, contribuiu para que a conversa ocorresse de forma mais fluida.

"No início me senti desconfortável, porque minha parceira queria me fazer perguntas no português e eu ficava minutos esperando-a formular. Nos trinta minutos do português não acho que teve um fluxo muito bom” (Leandro, FAT 1).

"Devo enfatizar que foi bem melhor do que a primeira sessão. Ela parecia mais preparada, em termos de língua, vocabulário, e eu estava mais consciente de seu nível linguístico" (Leandro, FAT 2).

"Penso que minha parceira tenha melhorado mais sobre sua pronúncia em língua portuguesa, o que ajudou no fluxo da conversa" (Leandro, FAT 4).

Também observamos a preocupação deles ao explorarem aspectos culturais sem reforçar estereótipos e o uso de recursos tecnológicos variados (chat, vídeos, imagens, compartilhamento de tela, músicas, entre outros), conforme nos trechos que seguem das FAT de Rafaela, Ísis, Leandro e Pedro.

"Eu falei do Carnaval no Rio, mas expliquei que não é assim em todo Brasil; há cidades que nem fazem uma festa muito grande" (Rafaela, FAT 1).

"Falei que o Brasil é muito grande e abarca muitas culturas e modos de viver o tempo todo" (Ísis, FAT 1).

“...modalizávamos todas as nossas falas sobre o que GERALMENTE comemos aqui ou lá” (Leandro, FAT 2).

"Pude dividir com meu parceiro diferentes gêneros musicais de diferentes regiões do Brasil, deixando claro que se trata de um país muito grande e salientando a diversidade cultural" (Pedro, FAT 3).

"Contei também dos jogos que jogamos deixando claro que é parte do meu contexto (e não necessariamente de todos)" (Rafaela, FAT 4).

"Quando estava falando sobre a cidade onde moro no Brasil, utilizei o recurso de compartilhar a tela para mostrar um mapa" (Pedro, FAT 1).

"Compartilhamento de tela, para mostrar fotos dos lugares; e chat, para escrever palavras no português" (Leandro, FAT 3).

Quanto às especificidades do português como língua estrangeira, língua do outro, apontamos a reflexão e a conscientização por parte dos parceiros brasileiros sobre aspectos que, até então, passavam despercebidos para os participantes que já eram professores, mas professores de línguas estrangeiras para brasileiros e sem experiência com o ensino de PLE.

No caso de Ísis, a título de exemplo, verificamos que ela considerava difícil analisar a própria língua materna inicialmente. Em sua última FAT, todavia, ela diz que as interações a ajudaram a estar mais consciente de como usa o português no dia a dia.

"Ainda é muito difícil para mim analisar o português" (Ísis, FAT 1).

"Estou bem mais consciente agora de como uso o português no dia a dia do que quando começaram as interações” (Ísis, FAT 4). 
Os registros de Leandro e Rafaela também apontam para conscientização sobre especificidades do ensino de PLE no que diz respeito a aspectos fonético-fonológicos, lexicais e discursivos.

"O quão dificil a pronúncia pode ser" (Leandro, FAT 2).

"Pude refletir acerca dos fonemas que causam confusão para aprendizes de português, especialmente diante da influência do espanhol" (Leandro, FAT 4).

"Fiquei com a impressão de que temos várias palavras para sermos debochados, como 'coitado', 'tadinho', 'judiação' (meu parceiro adorou)’' (Rafaela, FAT 4). "Percebi que utilizo muito 'pera' e terei que explicar para meu(s) parceiro(s) o que significa” (Rafaela, FAT 1).

É importante reiterarmos o fato de que os participantes realizaram apenas quatro interações e, embora os parceiros estrangeiros tivessem aulas de português em sua universidade concomitantemente às interações, a melhora de desempenhos em português é bastante significativa e indica, também, a contribuição positiva do parceiro brasileiro, conforme observado nos comentários de Leandro expostos anteriormente. Da mesma forma, Rafaela, Ísis e Lívia também apontam melhoras no fluxo da conversa com seus parceiros, além de outros relatos positivos das participantes no que concerne aos demais aspectos.

\section{"A conversa fluiu naturalmente de ambas as partes" (Rafaela, FAT 3). \\ "Novamente a parceira se preparou melhor e seu português se misturou bem menos ao espanhol. Também novamente as estruturas em geral estavam corretas, as correções foram mais ligadas a léxico e pronúncia” (Ísis, FAT 4). \\ "Pude perceber que o português dele melhorou significativamente desde nossa última interação, dessa vez precisei reformular algumas coisas, mas ele compreendeu a maioria sem maiores problemas" (Lívia, FAT 3).}

Com isso, finalizamos a presente subseção, que visou a compartilhar um enquadramento da condução do curso e considerações preliminares a respeito do desempenho dos participantes do curso enquanto professores de PLE.

\section{Recomeçando o ciclo a partir da avaliação da experiência}

O presente artigo propôs questões acerca de um curso de extensão de formação de professores de PLE que adotou o teletandem como um espaço para a prática de línguas estrangeiras e, ao mesmo tempo, como contexto de prática de ensino de PLE para os parceiros brasileiros, considerando as affordances oferecidas por esse contexto para o desenvolvimento de professores inicialmente apontadas por El Kadri (2018).

A ficha de acompanhamento/autoavaliação de teletandem (FAT) serviu como instrumento que apoiou as formadoras na condução dos encontros presenciais, proporcionando o acompanhamento e a intervenção na prática pedagógica dos parceiros brasileiros, observando suas dificuldades, fornecendo feedback necessário, explorando as affordances e, consequentemente, investigando as particularidades que o ensino de PLE demanda. 
Já na perspectiva do parceiro brasileiro de teletandem, professor de PLE em formação, a FAT foi um instrumento de autoavaliação na medida em que o aluno avaliou tanto o desempenho em português do seu parceiro estrangeiro como seu próprio desempenho no que concerne ao ensino de PLE. Em relação ao último aspecto, destacamos o confronto da identidade como brasileiro ao se deparar com o outro aprendendo sua língua materna, o reconhecimento de questões que perpassam a aprendizagem, a avaliação e o ensino de línguas, dentre outros.

Considerando o viés colaborativo da avaliação formativa (HAYDT, 1995), conduzir a mediação e o curso de extensão a partir dessa concepção de avaliação também ofereceu espaço de reflexão e aprendizagem para as próprias formadoras. Segundo Furtoso (2011), a atuação conjunta entre professor e aluno “(...) permite que ambos analisem seu desenvolvimento diante dos resultados obtidos” (p. 114). Desse modo, ao avaliarmos os participantes através das FAT, pudemos (re)pensar nossa própria prática como mediadoras e formadoras, (re)vendo objetivos do curso, conteúdos, metodologia e a própria prática avaliativa.

Dentre a aprendizagem como formadoras para uma futura edição de cursos dessa natureza, destacamos a importância de gravar as mediações (encontros presenciais). Desse modo, em investigação posterior, será possível analisá-las em conjunto com os demais dados (gravação das interações e FAT). Também constatamos a insuficiência de tempo no que concerne à duração desses encontros presenciais do curso (uma hora cada). Sugerimos um momento mais prolongado (entre uma hora e meia a duas horas) para que seja possível retomar os principais pontos expostos nas FAT, explorar devidamente as leituras sugeridas e proporcionar, aos participantes, maior espaço para que possam expor suas percepções, confrontando-as com as dos colegas e com os resultados de estudos discutidos a partir das leituras sugeridas.

Por fim, a partir das affordances acerca do desenvolvimento de professores observadas por El Kadri (2018), pudemos confirmar as seguintes (ressignificadas e, portanto, compreendidas no contexto de professores de PLE): criar empatia para a prática de idiomas por meio da telecolaboração, refletir sobre a língua materna como língua do outro e nas implicações que isso oferece para a atuação do professor de línguas estrangeiras, fornecer feedback cultural considerando a diversidade e a pluralidade, praticar tipos diferentes de feedback linguístico frente à cultura de aprender do parceiro e ampliar o uso de recursos tecnológicos para o ensino de línguas.

Destarte, considerando a breve análise por meio das FAT e as affordances supracitadas, constatamos que conduzir um curso por meio de uma perspectiva avaliativa e valendo-se do teletandem como metodologia (do curso) e contexto de ensino de PLE alinha-se às propostas de formação de professores que defendem uma abordagem de ensino intercultural (MENDES, 2011), à integração entre teoria e prática (ALVAREZ, 2011), às habilidades de operação da tecnologia (ALVAREZ, 2011) e à importância da autoavaliação para o desenvolvimento da autonomia (FURTOSO, 2011) do professor de PLE e para a reflexão sobre sua própria prática pedagógica.

\section{Referências}

ALVAREZ, M. L. O. Políticas de difusão e formação crítica em PLE: por uma formação por competências. In: MENDES, Edleise (org.). Diálogos Interculturais: ensino e formação em português língua estrangeira. Campinas, SP: Pontes Editores, 2011. p. 173-205.

ALMEIDA FILHO, J. C. P. Fundamentos de abordagem e formação no ensino de PLE e de outras línguas. Campinas, SP: Pontes Editores, 2011. 
BLOCK; D. CAMERON, D. (Eds.). Globalization and language teaching. New York: Routledge, 2002.

BONESI, P. G.; SOUZA, N. A. Fatores que dificultam a transformação da avaliação na escola. Estudos em avaliação educacional, Londrina, v. 17, n. 34, p. 129-154, maio/ago. 2006. Disponível em: <http://publicacoes.fcc.org.br/index.php/eae/article/view/2120/2077> . Acesso em: jan. de 2021.

CARLESS, D. Learning-oriented assessment: conceptual bases and practical implications. Innovations in Education and Teaching International. Hong Kong, v. 44, n. 1, 2007, p. 57-66.

CAVALARI, S. M. S. A auto-avaliação em um contexto de ensino-aprendizagem de línguas em tandem via chat. 243f. Tese (Doutorado em Estudos Linguísticos) - Universidade Estadual Paulista, São José do Rio Preto, 2009.

CAVALARI, S. M. S.; FRESCHI, A. C. A correção de erros e as relações entre avaliação por pares e autoavaliação no ambiente teletandem. Revista do GEL, v. 15, n. 3, p. 194-213, 2018.

EL KADRI, A. Affordances percebidas do teletandem na/para formação de professores de língua inglesa. 120 f. Dissertação (Mestrado em Estudos da Linguagem) - Universidade Estadual de Londrina, Londrina, 2018.

FICHER, D.; FREY, N. Checking for understanding: formative assessment techniques for your classroom. Alexandria: ASCD, 2007.

FRANCO, G. R. Aspectos linguísticos emergentes em sessões de Teletandem: uma análise a partir da conscientização da linguagem. 172f. Dissertação (Mestrado em Estudos Linguísticos) - Instituto de Biociências, Letras e Ciências Exatas, Universidade Estadual Paulista, São José do Rio Preto, 2016.

FRANCO, G. R.; RAMPAZZO, L. Estereótipos como sedimentadores de ideias de hegemonia em parcerias de teletandem institucional semi-integrado. Domínios de Lingu@gem, v.10, n.4, p.1302-1325, 2016.

FRESCHI, A. C. A avaliação por pares no teletandem institucional integrado: um estudo de caso sobre o feedback linguístico nas sessões orais em português. 212f. Tese (Mestrado em Estudos Linguísticos) - Universidade Estadual Paulista, São José do Rio Preto, 2017.

FURTOSO, V. A. B. Português para falantes de outras línguas: aspectos da formação do professor. Dissertação. 174 f. Dissertação (Mestrado em Letras) - Universidade Estadual de Londrina, Londrina, 2001.

FURTOSO, V. A. B. Desempenho oral em português para falantes de outras línguas: da avaliação à aprendizagem de línguas estrangeiras em contexto online. $285 \mathrm{f}$. Tese (doutorado) - Universidade Estadual Paulista, Instituto de Biociências, Letras e Ciências Exatas, São José do Rio Preto. 2011

FURTOSO, V. A. B; FERREIRA, M. J. Nem lá, nem cá, nem acolá: o português falado em espaços de aprendizagem desterritorializantes. In: ALVAREZ, M. L. O; GONÇALVEZ, L. (Org.). O mundo do português e o português no mundo afora: especificidades, implicações e ações. Campinas: Pontes Editores, p. 525-561, 2016. 
GIMENEZ, T. Caminhos e descaminhos: a pesquisa na formação de professores de língua estrangeira. the ESP, São Paulo, v. 19, n.2, p. 257-271, 1998. Disponível em:

<https://revistas.pucsp.br/index.php/esp/article/view/9912/7366> Acesso em: 14 jan. 2021.

HATTIE, J. Visible learning for teachers: maximizing impact on learning. New York:

Routledge, 2012.

HAYDT, R. C. Avaliação do processo ensino-aprendizagem. São Paulo: Ática, 1995.

KFOURI-KANEOYA, M. L. C. A formação inicial de professoras de línguas para/em contexto mediado pelo computador (teletandem): um diálogo entre crenças, discurso e reflexão profissional. 261f. Tese (Doutorado em Estudos Linguísticos) - Universidade Estadual Paulista, Instituto de Biociências, Letras e Ciências Exatas, São José do Rio Preto, 2008.

KFOURI-KANEOYA, M. L. C. A pesquisa em formação de professores de línguas, o ensino/aprendizagem de línguas no meio virtual e o teletandem. In: TELLES, J. A. (Org.) Teletandem: um contexto virtual, autônomo e colaborativo para aprendizagem de línguas estrangeiras no século XXI. Campinas, SP: Pontes Editores, 2009, p. 271-294.

KIELY, R. Developing Students' Self-Assessment Skills: The Role of the Teacher. In DAVIS, J. M. et al. (Eds.). Useful Assessment and Evaluation in Language Education. University Press, 2018, p. 3-20.

MENDES, E. O português como língua de mediação cultural: por uma formação intercultural de professores e alunos de PLE. In: MENDES, Edleise (org.). Diálogos Interculturais: ensino e formação em português língua estrangeira. Campinas, SP: Pontes Editores, 2011. p. 139-158.

MIQUELANTE, M. A. et al. As modalidades da avaliação e as etapas da sequência didática: articulações possíveis. Trabalhos em Linguística Aplicada, v. 56, n. 1, 2017, p. 259-299.

O'DOWD, R. Supporting in-service language educators in learning to telecollaborate. Language Learning \& Technology, v. 19, n. 1, 2015, p. 63-82.

O'DOWD, R. Emerging trends and new directions in telecollaborative learning. Calico Journal, v. 33, n. 3, 2016, p. 291-310.

OLIVEIRA, T. A. et al. (ed) Pode Entrar: Português do Brasil para Refugiadas e Refugiados. São Paulo: Agência da ONU para Refugiados (ACNUR), Curso Popular Mafalda \& Cáritas Arquidiocese São Paulo. Disponível em: https://www2.unifap.br/pamer/files/2016/11/PORTUGU\%c3\%8aS-DO-BRASIL-PARAREFUGIADOS-E-REFUGIADAS.pdf. Acesso em: jan. de 2021

PAIVA, V. L. M. O. Feedback em ambiente virtual. In: LEFFA, V. (Org.) Interação na aprendizagem das línguas. Pelotas: EDUCAT, 2003. p.219-254. Disponível em:

< http://www.veramenezes.com/feedback.htm $>$. Acesso em: 06 out. 2020.

PAIVA, V. L. M. O. Propiciamento (affordance) e autonomia na aprendizagem de língua inglesa. 2009. Disponível em: <http://www.veramenezes.com/affordance.pdf> Acesso em: 19 ago. 2020.

RAMOS, K. A. H. P; CARVALHO, K. C. H. P. de; MESSIAS, R. A. L. O ensino de português para hispanofalantes no contexto virtual do Teletandem. Portuguese Language Journal, v. 7, p. 1-23, 2013. 
ROCHA, N. A.; GILENO, R. S. S. Ensino e aprendizagem de português língua estrangeira (PLE): repensando o contexto de imersão. Revista EntreLínguas, v. 1, n. 2, 2015, p. 237-254, 2015.

ROSA, A. A. O desafio de se ensinar português para falantes de outras línguas: análise linguísticodiscursiva de um livro didático para o ensino do PLE. Anais do SIELP, v. 2, n. 1, 2012.

SALOMÃO, A. C. B.; SILVA, A. C. da.; DANIEL; F. G. A aprendizagem colaborativa em Tandem: um olhar sobre seus princípios. In: TELLES, J. A (Org.). Teletandem: um contexto virtual, autônomo, colaborativo para aprendizagem de línguas estrangeiras no século XXI. Campinas, SP: Pontes Editores, 2009. p. 75-92.

SCARAMUCCI, M. V. R. O professor avaliador: sobre a importância da avaliação na formação do professor de língua estrangeira. In: ROTTAVA, L.; SANTOS, S. S. (Orgs.) Ensino e aprendizagem de línguas: língua estrangeira. Editora da UNIJUI, 2006. p. 49-64.

\section{SILVEIRA, P. A autoavaliação e o desenvolvimento da autorregulação e da autonomia na} aprendizagem de língua inglesa em contexto de telecolaboração. 2017. 135f. Dissertação (Mestrado em Estudos da Linguagem) - Universidade Estadual de Londrina, Londrina, 2017. Disponível em: <http://www.bibliotecadigital.uel.br/document/?code=vtls000214888 > Acesso em: 14 jan. 2021.

TELLES, J. A.; ZAKIR, M. A.; FUNO, L. B. A. Teletandem e episódios relacionados a cultura. DELTA, v. 31, n. 2, 2015.

VAN LIER, L. From input to affordance: Social-interactive learning from an ecological perspective. In: LANTOLF. J. (Ed.). Sociocultural theory and second language learning. Oxford: Oxford University Press, 2000. p. 252-253.

VASSALLO, M. L.; TELLES, J. A. Ensino e aprendizagem de línguas em tandem: princípios teóricos e perspectivas de pesquisa. In: TELLES, J. A. (Org.) Teletandem: um contexto virtual, autônomo e colaborativo para aprendizagem de línguas estrangeiras no século XXI. Campinas, SP: Pontes Editores, 2009, p. 21-42.

ZAKIR, M. A. Cultura e(m) telecolaboração: uma análise de parcerias de teletandem institucional. $238 \mathrm{f}$. Tese (Doutorado em Estudos Linguísticos em elaboração) - Instituto de Biociências, Letras e Ciências Exatas, Universidade Estadual Paulista, São José do Rio Preto, 2015. 


\section{Apêndices}

Apêndice 1: Ficha de Acompanhamento/Autovaliação em Teletandem

\section{(1) Universidade \\ Estadual de Londrina}

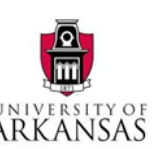

\begin{tabular}{|c|c|c|c|c|}
\hline \multicolumn{5}{|c|}{ FICHA DE ACOMPANHAMENTO TELETANDEM } \\
\hline \multicolumn{5}{|c|}{ 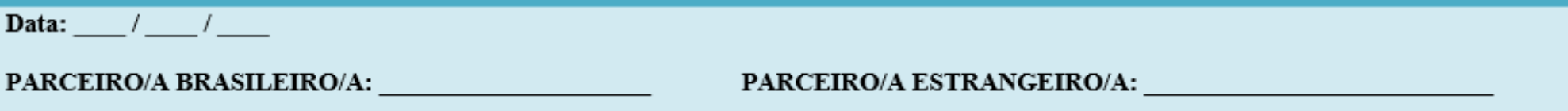 } \\
\hline Na sessão de hoje, fui capaz de... & SIM & $\begin{array}{l}\text { MAIS OU } \\
\text { MENOS }\end{array}$ & NÃO & COMENTE \\
\hline \multicolumn{5}{|l|}{$\begin{array}{l}\text { 1... esclarecer dúvidas e/ou fornecer explicações referentes a estruturas gramaticais da } \\
\text { língua portuguesa. Quais? }\end{array}$} \\
\hline \multicolumn{5}{|l|}{ 2... esclarecer dúvidas e/ou fornecer explicações referentes a aspectos lexicais. Quais? } \\
\hline \multicolumn{5}{|l|}{ 3... esclarecer dúvidas e/ou fornecer explicações sobre a pronúncia. Quais? } \\
\hline \multicolumn{5}{|l|}{$\begin{array}{l}\text { 4... usar estratégias como metalinguagem, sinônimos, etc. para fornecer explicações } \\
\text { e/ou esclarecer dúvidas. Tive alguma dificuldade? Se sim, qual/is? }\end{array}$} \\
\hline \multicolumn{5}{|l|}{ 5... abordar questões de minha cultura sem reforçar estereótipos. Dê exemplos. } \\
\hline \multicolumn{5}{|l|}{$\begin{array}{l}\text { 6... utilizar a tecnologia como ferramenta de apoio para o ensino-aprendizagem. Quais } \\
\text { recursos utilizei? Em que momentos esses recursos foram utilizados? }\end{array}$} \\
\hline \multicolumn{5}{|l|}{ 7... manter o fluxo da conversa com meu parceiro. Se sim, comente. } \\
\hline \multicolumn{5}{|l|}{$\begin{array}{l}\text { 8... me tornar mais consciente sobre aspectos de minha língua materna. Quais } \\
\text { aspectos? }\end{array}$} \\
\hline \multicolumn{5}{|l|}{$\begin{array}{l}\text { 9... providenciar feedback para meu parceiro. Tive alguma dificuldade? Se sim, } \\
\text { qual/is? }\end{array}$} \\
\hline 10. Outros. & & & & \\
\hline
\end{tabular}

